\title{
Victimization in Childhood as a Factor Conditioning Risk Behaviors in the Group of Polish Adolescents
}

\author{
Marta Makara-Studzińska ${ }^{1}$, Bożena Śpila ${ }^{2}$ \\ ${ }^{1}$ Independent Laboratory of Psychical Health, Medical University of Lublin, Lublin, Poland \\ ${ }^{2}$ Department of Psychiatry, Medical University of Lublin, Lublin, Poland \\ Email: makara@go2.pl
}

Received December $2^{\text {nd }}, 2011$; revised January $17^{\text {th }}, 2012$; accepted February $23^{\text {rd }}, 2012$

\begin{abstract}
The aim of this work is an attempt to determine the relationship between experiences of violence in childhood and health and life risk behaviors among Polish youth. The studied group consisted of patients 14 - 18 years old from a dozen or so Polish centers treating young people with risk behaviors, mental disorders and dependence disorders. Early Trauma Inventory (ETI) and our Scale of Healthy Behaviors (SHB) were used in the study. Results: Young people after suicidal attempts and with substance abuse the most often had physical violence experiences in childhood. Adolescents with eating disorders had experienced emotional and sexual violence.
\end{abstract}

Keywords: Component; Formatting; Style; Styling; Insert

\section{Introduction}

For a long time we can observe reports about influence of experienced violence in childhood to later risk behaviors (as eating disorders, substance abuse or suicidal behaviors) in adolescence. Smolak and Murnen (2002) conducted meta-analysis of relationship between sexual abuse in childhood and eating disorders, and starting-point were inconsistent results found by other authors. Some of them (Pope \& Hudson, 1992) reviewing literature conclude that due to this divergence such relationship does not exist, however others (Wonderlich, Brewerton, Jocic, Dansky, \& Abbott, 1997) prove that sexual abuse in childhood is a risk factor. In their meta-analysis, Smolak and Murnen (2002) studied on the one hand power and stability of relationship between sexual abuse in childhood and eating disorders, and on the other hand-methodological factors, that may have an influence on results inconsistency. Authors found a small positive correlation between sexual abuse and eating disorders, but this correlation was heterogeneous.

Clinicians' works and reports however point to high relationship between sexual abuse in childhood and eating disorders, especially in genesis of bulimia-as a escape reaction to relationships in the families, that are specifically dysfunctional, aggressive, related to sexual abuse and seduction child by a parent (Briere, 1992; Fergusson \& Mullen, 1999).

Until half of 70-ties of XX century, the most of studies concerning reasons of alcohol drinking and substance abuse concentrated almost exclusively on men. When women were started to be studied, it was clear that many important problems related to this area concerned sexuality (Wilsnack, 1984). There were more and more data that many of studied women experienced sexual abuse in childhood (Malinosky-Rummell \& Hansen, 1993; Miller \& Downs, 1995). This result made a lot of clinicians to state that experiencing of sexual violence in childhood may be etiological risk factor for development of problems with substance abuse (Miller \& Downs, 1995; Root, 1989). It was also suggested that experiencing of physical violence in child- hood can be similar risk for many people (Malinosky-Rummell \& Hansen, 1993; Miller \& Downs, 1995). Polish studies (Cekiera, 1985; Kowalewicz \& Malinowska, 1983; Piotrowski, 1976; Stankowski, 1988), found that parents, especially fathers of respondents taking psychoactive substances reported a greater tendency toward using physical punishments in children and adolescents. In the study of Marzec-Tarasińska (1998), Polish adolescents with substance abuse perceive their fathers as using punishments-physical and humiliating ones.

Suicidal behaviors are other behaviors of very high dangerous. Herman (1981) informed that $38 \%$ of her patient with sexual abuse, had suicidal attempts in history (in the control group only 5\%); De Young (1982) found in the group of sexual violence victims - $68 \%$ individuals who attempted suicide, $2 / 3$ of them - many times. Bryer et al. (1987) said that in women patients with history of suicidal behaviors or attempts - he found 3 times more often physical and/or sexual abuse in childhood.

Brzozowska in her literature review (2004) points to importance of mental and behavioral disorders, among them aggressive impulsivity, present in harmed persons, which much increases suicidal risk in them.

Many of studies seem to confirm relationship between violence experiencing in childhood and engaging in life and health risk behaviors, as eating disorders, alcohol and substance abuse and suicidal behaviors. However it is important that significance of violence in etiology of such behaviors is multiple and this correlation must be placed in the context of multidimensional model containing biological, psychological and sociocultural risk factors.

The aim of this paper is an attempt to determine relationship between violence experiencing in childhood and life and health risk behaviors in Polish adolescents; it is a trial to complex scientific description of this problem with regard to all types of violence (physical, sexual, emotional) and various risk behaviors, as substance abuse, eating disorders and suicidal behaviors. 


\section{Study Procedure}

The group consisted of 299 persons. The studies were conducted in years 2003-2006 in all Poland. We studied young people in the age of $14-18$ years with life and health risk behaviors. This age range was chosen because this is the most of all risk behaviors in this age group. We used methods suitable for the group age and for their level of auto-reflection and skills in using questionnaire methods.

The group consisted of the patients of a dozen or so Polish centers treating adolescents with risk behaviors. First we got positive opinion of the Bioethical Board of Medical Academy in Lublin (decision number KE-0254/353/2003 at 27.11.2003) about realization of this clinical project.

Then we obtained:

- Spoken or written approval of chief of the center;

- Written consent of patient's parents or one parent;

- Written consent of the patient.

Each patient was given the envelope with the instruction and test material. Respondents can perform tests anonymously. We included only these persons, from whom we had obtained their and their parents consents and they met following inclusion criteria:

1) Being treated due to one of life of health risk behaviors diagnosed by the treating center;

2) Lack of symptoms severe somatic disorders and organic damage of central nervous system;

3) Being during the first step of treating program in the specialistic centre;

4) Age of 14 - 18;

5) Lack of symptoms of mental retardation;

6) Lack of criteria of psychotic disorders.

Patients have been studied in the centre or department, where they live due to their treatment. All of clinical group were in the first step of treatment - individuals after suicidal attempt from 1 to 3 days after it, individuals abusing substances from 2 to 3 months, patients with eating disorders from 1 to 3 week of hospitalization.

Following research steps were established. The talk was started from current frame of mind, circumstances and motivation of treatment - it was due to crisis interventions rules consisting in touch subject that is the most important for the patient. Next demographic and family data were gathered and in the last step we used the Early Trauma Inventory (ETI, J. D. Bremner) and the Scale of Healthy Behavior of our construction.

The Early Trauma Inventory was developed due to need of full and reliable assessment of child trauma for research and clinical purposes by the team under the leadership of professor Bremner from the Department of Psychiatry Emory University School of Medicine in Atlanta, USA. Polish adaptation of ETI was done by research team (Śpila, Makara-Studzińska, Chuchra, Grzywa) from the Department of Psychiatry Medical Academy in Lublin, Poland, in years 2002-2005. The Early Trauma Inventory in Polish version consists of 62 questions divided into 4 parts: general stress experiences-24 questions (in the selfquestionnaire version 31 questions), physical abuses - 9 questions, emotional abuses -7 questions, sexual abuses-15 questions. Severity of each abuses is assessed for ever developmental periods: pre-school phase ( 0 - 5 years), elementary school phase (6 - 12 years) and maturation phase (13 - 18 years). Second subpoint assesses frequency of events: from one a year to everyday. Third subpoint determines the perpetrator of abuse. Each of subscales ends in assessment of subjective influence on individual, measured in 7-point Likert scale: from 0 - very negative influence to 6-very positive, in terms of emotions, social functioning and social relationships.

Some difficulties happened during performing Polish adaptation of this measurement. After many consultations it was decided to leave version of translation consistent with the American one. The most difficult problem during translation process was adjustment of Polish vocabulary to contents of subscale relating to sexual abuses. Similarly to original version, question about veracity of memorial traces regarding bad experiences from childhood was problematic due to mechanisms of trauma abjuration. After performing statistics it was clear that the adaptation was highly reliable, Cronbach's alpha coefficient for all Inventory was 0.88 .

The second measurement used in the study was the Scale of Healthy Behavior (SHB) of our own construction, which serves to examine children and adolescents, both healthy and ill. It allows to determine preferred behaviors, both pro- and antiwholesome with regard to its kinds.

This device can be used in the healthy behaviors of children and adolescents and in creating healthy education programs for individuals from 10 years old. The measure of healthy behaviors of children and adolescents can be also used in health promotion programs teaching new skills related to healthy behaviors.

The scale SHB is self-report one. The examination may be performed individually or in group. Performing time depends of patient's age and reading skills, but generally it does not extend 30 minutes. The scale consists of 131 statements, which are divided into following categories: personal data and family situation, healthy attitudes and values, eating, physical activity, leisure spending, personal hygiene, dreaming, smoking cigarettes, alcohol and substance taking, symptoms of social maladaptation, getting various forms of support, life attitude.

\section{Characteristics of the Group}

In the examined adolescents $(n=299)$ with health and life risk behaviors the following subgroups were found:

1) Adolescents after suicidal attempts, whose results were signed as G-SUI;

2) Adolescents abusing substances G-NU;

3) Adolescents with eating disorders G-ZO.

The group after suicidal attempt (G-SUI) consisted of 99 individuals, the group with substance abuse (G-NU) -100 persons and the group with eating disorders (G-ZO) also 100 persons.

The groups were divided into the subgroups regarding to dominate type of risk behavior. The group G-SUI was divided into subgroup after the first suicidal attempt (G-SUI1) and the subgroup after more than one attempt (G-SUI2+). In the subgroup after the first suicidal attempt were 53 persons and in the second group - 46. The group of substance abuse was divided into the subgroup with alcohol abuse $(\mathrm{G}-\mathrm{Al}, \mathrm{n}=46)$ and with drugs abuse $(\mathrm{G}-\mathrm{Nar}, \mathrm{n}=54)$. The group with eating disorders was divided into patients with anorexia nervosa $(\mathrm{G}-\mathrm{AN}, \mathrm{n}=54)$ and with bulimia nervosa (G-BN, $n=46)$ (Table 1).

Percentage age distribution in the studied groups was as follow: individuals in the age of $16-17$ years were the biggest subgroup (Table 2). Risk behaviors as first suicidal attempts, drugs abusing and anorexia nervosa were the most often in the age range of 14 - 15 years. We found significance amount of next 
Table 1.

Characteristic of the studied group regarding numerous and gender.

\begin{tabular}{cccccccc}
\hline \multirow{2}{*}{$\begin{array}{c}\text { Studied } \\
\text { groups }\end{array}$} & \multirow{2}{*}{ Sub groups } & \multicolumn{2}{c}{ Numerous } & \multicolumn{2}{c}{ Boys } & \multicolumn{2}{c}{ Girls } \\
\cline { 2 - 8 } & & $\mathrm{N}$ & $\%$ & $\mathrm{~N}$ & $\%$ & $\mathrm{~N}$ & $\%$ \\
\hline \multirow{2}{*}{$\begin{array}{c}\text { Suicidal } \\
\text { attempt }\end{array}$} & First & 53 & 53.54 & 18 & 33.96 & 35 & 66.04 \\
& More than one & 46 & 46.46 & 24 & 52.17 & 22 & 47.83 \\
& Together & 99 & 100.00 & 42 & 42.42 & 57 & 57.58 \\
& Drugs & 54 & 54.00 & 54 & 100.00 & 0 & 0.00 \\
Abusing & Alcohol & 46 & 46.00 & 46 & 100.00 & 0 & 0.00 \\
& Together & 100 & 100.00 & 100 & 100.00 & 0 & 0.00 \\
\multirow{3}{*}{ Eating } & Anorexia & 54 & 54.00 & 0 & 0.00 & 54 & 100.00 \\
disorders & Bulimia & 46 & 46.00 & 0 & 0.00 & 46 & 100.00 \\
& Together & 100 & 100.00 & 0 & 0.00 & 100 & 100.00 \\
\hline
\end{tabular}

suicidal attempts, both alcohol and drugs abusing and both types of eating disorders in the group $16-17$. The most often behavior in the age group 18 - 19 years were: next suicidal attempts, alcohol abusing and bulimic behaviors (Table 2).

In the subgroup after the first suicidal attempt we found $81.13 \%$ people in the age of $16-17$ years, $11.32 \%$ in the age of $14-15$ years and $7.55 \%-18-19$ years. In the subgroup with more than one suicidal attempt we found $58.7 \%$ individuals 16 - 17 years old, $39.13 \% 18$ - 19 and $2.71 \% 14-15$ years old.

In the subgroup of adolescents abusing drugs we found $85.19 \%$ in the age of $16-17$ years, $3.7 \% 18-19$ years, $11.11 \% 16-17$. In the subgroup of adolescents abusing alcohol we found $84.78 \%$ persons of age $16-17,2.7 \% 14-15$ and $10.4 \%$ of $18-19$.

In the subgroup of girls with anorexia, $77.78 \%$ of them was in $16-17$ years old, $1.85 \%$ was of $18-19$ years, and $20.37 \%$ of 14 - 15 . In the subgroup of girls with bulimia, $71.74 \%$ of them was $16-17$ years old, $4.3 \%$ of $14-15$, and $23.91 \%$ of $18-19$ (Table 2).

In the next step, we were looking for complex relationships between childhood trauma experiences in the group of adolescents with health and life risk behaviors.

First we performed the analysis regarding this subject in whole group, it means 299 individuals. Next step it was the analysis of interrelationships for each type of risk behavior in adolescents. The results were obtained using correlation procedure, discriminance analysis and concentrations analysis.

We looked for typology of experienced violence by dividing the whole group (adolescents showing different types of health and life risk behaviors) into the subgroups in the empirical method. It was important to establish what subgroups can be find regarding to differentiation of patients' results in experiencing violence.

The analysis of concentrations was the method used to do this division. This sort of analysis leads to grouping of subjects (persons) based of their similarity determined mathematically (Marek \& Noworol, 1987). The used technique of concentrations analysis is called the method of average weighted connections between the groups. Hierarchical concentrations analysis gives an ability to divide subjects into optional number of subgroups based on which level of analysis can be regarded as satisfactory solution. The auxiliary criterion is significant increase of concentration coefficient between following analysis levels (the greater concentration coefficient the smaller probability of subjects forming group).

In this case concentration analysis was performed to differentiate types of experienced violence in studied adolescents with risk behaviors.
Table 2.

Characteristic of the studied group regarding to age.

\begin{tabular}{cccccccc}
\hline \multirow{2}{*}{$\begin{array}{c}\text { Studied } \\
\text { groups }\end{array}$} & Sub groups & \multicolumn{7}{c}{ 14 -15 years old } & $16-17$ & years old & $18-19$ years old \\
\cline { 3 - 8 } & & $\mathrm{N}$ & $\%$ & $\mathrm{~N}$ & $\%$ & $\mathrm{~N}$ & $\%$ \\
\hline \multirow{2}{*}{$\begin{array}{c}\text { Suicidal } \\
\text { attempt }\end{array}$} & First & 6 & 11.32 & 43 & 81.13 & 4 & 7.55 \\
& Next & 1 & 2.17 & 27 & 58.70 & 18 & 39.13 \\
& Together & 7 & 7.07 & 70 & 70.71 & 22 & 22.22 \\
& Drugs & 6 & 11.11 & 36 & 85.19 & 2 & 3.70 \\
Abusing & Alcohol & 4 & 2.70 & 39 & 84.78 & 6 & 10.40 \\
& Together & 11 & 11.00 & 85 & 85.00 & 4 & 4.00 \\
\multirow{2}{*}{ Eating } & Anorexia & 11 & 20.37 & 42 & 77.78 & 1 & 1.85 \\
disorders & Bulimia & 2 & 4.35 & 33 & 71.74 & 11 & 23.91 \\
& Together & 13 & 13.00 & 75 & 75.00 & 12 & 12.00 \\
\hline
\end{tabular}

Next, to confirm reliability of the division and to state if there are significant differences between created groups-these groups were compared based on psychological and health behaviors variances using variance analysis ANOVA.

The general idea of the division was to create such subgroups that each of its can consist of the adolescents with characteristic results range. It was important, that subject with determined results range from ETI would create one subgroup. Results of three general scales of ETI were entered to the concentrations analysis. The division using hierarchical concentrations analysis leads to reveal both typical and non-typical forms of experienced violence, because it gives information - visually showed on the dendrogram - about position of each case in the group. Due to character of this work-the division into less number of subgroups is preferred, because the analysis on the high level of generality is concerned.

\section{Results}

\section{Types of Violence}

Thanks to concentrations analysis 4 subgroups were revealed (Table 3) and it reflects four types of experienced in childhood violence in the group of adolescents with health and life risk behaviors. The division of the group into 4 subgroups seemed to be substantiated based on the statistical (formal) and essential issues. Created subgroups have various number of subject, what makes the comparison to be more difficult (Table 3).

The comparison of results regarding types of violence in the range of three main scales of ETI using variance analysis ANOVA revealed:

Concentration $\mathrm{Nr} 1$ concerns combined physical-emotional violence;

Concentration $\mathrm{Nr} 2$ concerns physical violence;

Concentration Nr 3 concerns sexual violence;

Concentration $\mathrm{Nr} 4$ concerns emotional violence.

1) Type A-physical-emotional violence;

2) Type B-physical violence;

3) Type C-sexual violence;

4) Type D-emotional violence.

1) Type A-physical-emotional violence

This group was the smallest one. It comprise of 28 individuals. This subgroup has high results in both physical and emotional violence scales and low results in sexual violence scale. Due to this fact we create name of this subgroup-combined violence group, because both types of violence was present. In this type children experienced punishments with physical power 
Table 3.

The comparison results regarding types of violence in the range of three main scales of ETI using variance analysis ANOVA.

\begin{tabular}{cccccccccccc}
\hline & \multicolumn{2}{c}{ Physical-emotional violence } & \multicolumn{2}{c}{ Physical Violence } & \multicolumn{2}{c}{ Sexual violence } & \multicolumn{2}{c}{ Emotional Violence } \\
\cline { 2 - 11 } & $\mathrm{M}$ & $\mathrm{SD}$ & $\mathrm{M}$ & $\mathrm{SD}$ & $\mathrm{M}$ & $\mathrm{SD}$ & $\mathrm{M}$ & $\mathrm{SD}$ & $\mathrm{F}$ & $p$ \\
\hline Physical violence & 700.00 & 153.14 & 730.35 & 136.52 & 349.25 & 326.77 & 66.14 & 70.14 & 305.72 & $* * *$ \\
Emotional violence & 494.36 & 117.74 & 104.31 & 66.09 & 402.56 & 242.41 & 564.16 & 96.89 & 177.44 & $* * *$ \\
Sexual violence & 6.07 & 10.43 & 4.35 & 9.94 & 57.97 & 14.62 & 5.16 & 9.47 & 235.45 & $* * *$ \\
\hline
\end{tabular}

${ }^{*} p \leq .05 ;{ }^{* * *} p \leq .01 ;{ }^{* * *} p \leq .001$.

together with destroying in child skills of right social functioning and in development of his personality. Emotional violence may comprise various types of verbal aggression and hostility toward the child or such actions as: frightening, blackmailing, extorting of loyalty, terrorizing, humiliating, various kinds of over-control, making guilty feelings, stating the child in the situation of contradictory desires and statements, non-respecting of personal dignity and privacy of the child. It can also comprise avoiding of interactions with child, his isolation, emotional rejecting and neglecting of his emotional needs, ignoring and depriving of stimulations.

We also analysed what risk behaviors were present in adolescents who experienced this type of violence. The most numerous was subgroup after suicidal attempts (46.43\%), psychoactive substance abuse subgroup was smaller (39.29\%) and the smallest was subgroup with eating disorders (14.29\%).

2) Type B-physical violence

This type was the biggest subgroup in our study, it consists of 85 individuals. These subjects had high results in the physiccal violence scale and low results in the emotional and sexual violence scales.

In this type, physical violence distinctly dominate. It comprises of behaviors that can be present in active form (slaps, beating with fist, with an object, beating blindly, kicking, forcing to defaming services, scalding, wounding, strangling, attempting or committing murder) or passive one-various kinds of prohibitions (house leaving, going, speaking). This type of violence also comprises aggressive and destructive behaviors. Aggressive behaviors are pointed to determined thing and its aim is to making pain, frightening or making annoyance. Its can be simple (with rather short time of acting) - striking, pushing, tearing pulling out, drawing, pinching, pressing, strangling, kicking, aping, spitting, biting, throwing, blowing, stinging) or complex (longer) - fights or frightening. The aim of destructive behaviors is to damage of destroy things and its comprise: tearing, blowing, throwing, kicking and attacks of anger.

The most of persons with this type of violence experienceshad risk behaviors as psychoactive substance abuse- $70.59 \%$. In the subgroup after suicidal attempts $29.41 \%$ of them experienced this type of violence. It is worth to note, that this type of violence did not present in the subgroup with eating disorders.

3) Type $\mathrm{C}-$ sexual violence

This subgroup consists of 32 individuals with high scores on sexual violence scales and low scores on other violence scales. This type of violence includes including the child in sexual activity, that he can't fully understand and give conscious consent to it and/or he is not developmentally mature to it and he can't agree to it in legally valid manner and/or that is discordant with legal or custom norms of the society.

In this type of behaviors there are behaviors with penetration or without it (touching of intimate parts of body, kissing with sexual context and touching of intimate body parts of partner). There are also exhibitionism, voyeurism (looking furtively, making child to show its genitalia), including child in watching or producing pornographic materials, making sexual propositions to child or verbal molesting of child. This type also includes talks with sexual content with child, showing anatomy or sexual activities (masturbating in the presence of child, making child a during sexual courses), looking furtively (watching child during taking a bath, physiological activities, forcing to pose to pornographic photos or films). This type of violence consists also of child prostitution, trade in child, child pornography. In the subgroup with eating disorders there was the biggest subgroup of this type of violence victims (53.75\%), and in the subgroup after suicidal attempts $(30.38 \%)$. There were only $1.88 \%$ of them in the subgroup with substance abuse.

4) Type D-emotional violence

There were 74 individuals in this subgroup. They had high scores in the emotional violence scale and low scores in the physical and sexual violence.

Emotional violence it is making impossible such basic needs as: safety need, need to live in the environment free from hostility and violence, need to stable contact with emotionally level-headed protector and need of sense of own dignity. In this type of violence there are the following forms of mental maltreating: rejecting (verbal and non-verbal rejecting or humiliateing by protector), frightening (threatening child with making physical injury or exposing child or its love person to danger); isolating (refusing child to contacts with other children or adults); exploiting/depraving modeling, allowing or encouraging to antisocial behaviors); denying emotional reactions (ignoring child's need for interactions, non-showing positive emotions, lack of emotions during interactions with child); neglecting of mental, educational and health development of child (ignoring or inability to satisfy these needs). In practice type D of violence it is repeated behavioral pattern of protector or extremely drastic event (or events), that make child feeling unloved, unwanted, bad, worthless, menaced and feeling that he is worth only in this situation when he satisfy other people needs.

The Type D violence can be defined as hostile or neglecting parents behaviors, that (if its appear permanently or drastically) influence child's dignity, weaken sense of self-realization, reduce sense of belonging and make impossible healthy and normal development.

This type of violence was the most often experienced in the subgroup with eating disorders- $76 \%$ and in the subgroup after suicidal attempts - $23 \%$, and only in $1 \%$ in the subgroup with substance abuse.

The found results point to presence of significant correlations between type of violence used by parents and child's gender. The biggest group of combined violence it were boys- $57.14 \%$. In the type of physical violence also were mostly boys as vic- 
tims $-82.35 \%$. In the group of sexual violence, girls were the biggest group $-98.50 \%$. Similar trends were noted in the emotional violence, where girls dominated-86.49\%. Summarizing, the most often physical or combined violence is used to boys, and emotional or sexual violence - to girls.

Correlation analyses led to identification of relationship between adolescents risk behaviors and experienced violence in the childhood.

\section{Type of Violence and Kind of Risk Behaviors}

We performed an analysis of gathered types of violence regarding to show various kinds of health and life risk behaveiors (Table 4).

Adolescents after suicidal attempts the most often experienced physical violence (type B) in childhood (25\%). Also adolescents with substance abuse the most often experienced physical violence in childhood $(60 \%)$. The sexual violence (type C) was noted in this group, too (75).

Adolescents with eating disorders the most often experienced emotional violence (type D, 56.68\%) and sexual violence (26\%). The girls with anorexia nervosa the most often experienced emotional violence $(57.41 \%)$ and sexual one (24.07\%). The physical violence was not noted in this group. The girls with bulimia nervosa the most often experienced emotional violence $(54.35 \%)$ and sexual one $(34.17 \%)$.

\section{Discussion}

In the summary of trends in the literature regarding violence against children in the period of 22 years, Behl et al. (2003) state that $32.7 \%$ works concerned sexual violence, $20.2 \%$ physical violence and only $4.2 \%$ - emotional violence. Speculating about reasons of under-representation of emotional violence it was pointed, that physical and sexual violence can be much easier operationated for research purposes. There is lack of accordance as to what this type of violence consists of, its victims seldom report it, the signs are not specific and there is lack of pathognomonic effects during the tests (Thompson \& Kaplan, 1996). Focusing on the studies on physical and sexual violence against children may also be a reaction to cases showed by media (Behl, Conyngham, \& May, 2003).

Researchers often study influence of combined violence onto a victim and they state that experiencing of various kinds of violence is more harmful for them (Dube, Anda, Felitti, Chapman, Williamson, \& Giles, 2001; Edwards, Holden, Felitti, \& Anda, 2003; Teicher, Samson, Polcari, \& McGreenery, 2006). Many of authors identify emotional violence as an essential kind of violence (Cicchetti, 1990; Garbarino, Eckenrode, \& Bolger, 1997; Hart, Brassard, Karlson, 1996; Teicher, Samson, Polcari, \& McGreenery, 2006). But a lot of authors concentrate on studying of influence of physical and/or sexual violence, stating especially devastating influence of combination of these two kinds of violence for victim. For example, adolescents who experienced these two kinds of violence seem to be especially exposed to the risk of substance abuse (Luster \& Small, 1997; Moran, Vuchinich, \& Hall, 2004).

Based on the literature and prevailing own studies it was found that kinds of violence specified by researchers cannot be fully used in the victims of early-childhood violence. This was the reason to look for own typology of violence.

After using of statistical analysis we got own typology of violence experienced in the early childhood. The following types of violence were specified: type of combined physicalemotional violence, physical violence, sexual violence and emotional violence. This obtained typology allows to detailed characteristics of defined types of violence.

Type A of violence it is using of combined physical and emotional violence - both in similar severity. This kind of violence it is using temporarily punishments with physical power and various forms of verbal aggression and hostility to child. Among studied adolescents with risk behaviors, the biggest group of victims it was group after suicidal attempts- $46.43 \%$; the group with substance abuse it was $39.29 \%$ and adolescents with eating disorders- $14.29 \%$. Other authors point to trend of various kinds of violence to coexist. Ney et al. (1993) hypothesize that different forms of maltreating are seldom present separately and singly. Only $5 \%$ of studied groups experienced separate, isolated kinds of violence of neglecting. It means that treating a child as a victim of only one form of violence-is a mistake. Similarly, Farmer and Owen (1995) inform that in most of children entered to the Protection Register, more than one form of maltreating was stated. The literature point that increase of types of violence meant increase of both negative effects for mental health (Higgins \& McCabe, 2000) and physical problems (Moeller, Bachmann \& Moeller, 1993). The results of some studies (Claussen \& Crittenden, 1991; Crittenden, 1988) showed that physical maltreating is connected with mental one in most of cases. Additionally Clausen and Crittenden (1991) noticed that stating fact of mental violence predicted of developmental disorders in child, while degree of physical violence was not good predictor.

In the Type B of violence all physical violence forms dominate. In adolescents with risk behaviors, the biggest group was that of substance abuse- $70.59 \%$. In the group after suicidal attempts, $29.41 \%$ of them experienced this kind of violence. The increased level of experienced physical violence in childhood, in boys and girls with substance abuse-was found in the literature review by Simpson and Miller (2002). Similarly, Evans et al. (2005) in their review stated that for adolescents with experienced physical violence in childhood-suicidal behavior was more probable than in comparison group. It is worthy to notice, that type $\mathrm{B}$ of violence was not present in the studied

Table 4.

The comparison of results regarding types of violence in the studied groups.

\begin{tabular}{|c|c|c|c|c|c|}
\hline \multirow{3}{*}{ Studied groups } & \multicolumn{4}{|c|}{ Type of Violence } & \multirow{3}{*}{ Together } \\
\hline & TYPE A & TYPE B & TYPE C & TYPE D & \\
\hline & Physical-emotional violence & Physical violence & Sexual violence & Emotional violence & \\
\hline G-SUI & $13 \%$ & $25 \%$ & $11 \%$ & $18 \%$ & $33 \%$ \\
\hline G-NU & $11 \%$ & $60 \%$ & $7 \%$ & $0 \%$ & $33 \%$ \\
\hline G-ZO & $4 \%$ & $0 \%$ & $26 \%$ & $56 \%$ & $33 \%$ \\
\hline Together & $9 \%$ & $28 \%$ & $11 \%$ & $25 \%$ & $100 \%$ \\
\hline
\end{tabular}


adolescents with eating disorders. It can be explained by fact, that this group consisted of girls, which-it will be mentioned later- to a small extent experienced physical violence.

The Type $\mathrm{C}$ of violence it is including child in sexual activity, which child can't fully understand and give consent for it. The type $\mathrm{C}$ of violence also include child pornography and prostitution. The biggest group of the type $\mathrm{C}$ victims was among adolescents with eating disorders $-53.75 \%$ and after suicidal attempts $-30.38 \%$. The smallest group with this type of violence was among adolescents with substance abuse-1.88\%. Salter (2003) observed different relationships. Writing about techniques of mental pain control used by sexual violence victims, she found not only suicidal behaviors but also alcohol and drug abuse. Simpson and Miller (2002) in the literature review analyzing correlations between substance abuse and violence-stated experience of violence (including sexual one) may be important risk factor for development of problems with alcohol and drugs in female gender. The small percentage of sexual violence experiences in the group with substance abuse in our study-is related with fact, that NU group was all consisted of boys, which - it will be mentioned later-to a small extent experienced sexual violence or they did not report it.

Type D of violence it is only emotional violence using. This type of violence includes the following: making impossible for child to meet such basic needs as need of safety, need of living in the environment free of hostility and violence, need of stable contact with level-headed protector and of own dignity sense. The type D of violence was defined as hostile or neglecting parents' behavior, that destructively influences child's dignity, weakening sense of self-realization in him, reducing sense of belonging and making impossible healthy and correct development for him. The biggest group of this type violence victims was in adolescents with eating disorder-75.68\% and in the group after suicidal attempts- $23.32 \%$ and only $1.00 \%$ in the group of adolescents with substance abuse. The observed relationship between emotional violence and eating disorders is consistent with results of Kent et al. (1999) and Kent and Waller (2000), who found influence of emotional violence experiences in childhood on the eating disorders is greater than influence of sexual and physical violence. Also works of Hund and Espelage (2006) point to presence of correlation between emotional violence in childhood and eating disorders in the later life. In the study of Bifulco et al. (2002), emotional violence experiences in childhood was related to suicidal behaviors in later life. However, Moran et al. (2004) found relationship between emotional violence experiences and substance using by adolescents, but it was the weakest-in comparison with other analyzed types of violence.

Performed studies have several imperfections. The studies have cross-sectional character, so its do not give direct information about changes of maturational period, its phases and dynamics. Yet its allow to establish the correlates of specific variables characterizing for risk behavior and relationship between experiences of early violence and these behaviors in the adolescence period. Limitations resulting from using of our research method do not allow to show causality of observed correlations, it remains an area for further works.

As a questionnaire studies, our studies are susceptible on cheating. The next limitation results from selection of analyzed variables. In this case, weaker sides of the studies point to possible directions of future studies. It would be worthy to perform more analyses, for example measurement of stress severity, sense of life or analysis of life events-all its are important variables in adolescents.

The subject of life events - includes not only facts directly preceding appearing of risk behavior, but also it should include universal analysis of biography. It is need to profound studies analyzing cases, what may give more full picture of taking risk behaviors by adolescents and to help in realizing of individual ways of development during the adolescence.

Specifically longitudinal studies would be valid, its allow to analyze of respective steps of this process. The groups defined by concentrations analysis suggest need of this kind of research.

First it seems interesting what is subjective interpretation of various life events and changes occurring during the life in the various groups of adolescents defined in this study. It is possible that answers to these questions can be obtained by the analysis of idiographic material.

Second, it is worthy to perform longitudinal research to state of changes dynamics in personality functioning in victims of various kind of child violence. The way of interpreting of the life events must be taken under consideration.

Third, it is worthy to remind about value of interdisciplinary studies regarding adolescents' risk behavior and violence in childhood. This kind of studies make chance to global define of factors and psychological, social and biological changes, and more full picture of the problems is possible due to it; and then we avoid of risk of explanation complex phenomena by one kind of causes. The view of life cycle considerably steps over static personality picture, creating the bases for study changes in the way of functioning and adaptation in the various life periods in early violence victims. Such analyses should be enriched be exploration meanings what victim gives to life events and various elements of personal experience, and as a result of them-some attitudes, values and personal psychosocial functioning ways are changing.

Integration attitude make chances to multi-aspectional and deep cognition of changes related to adolescence, taking risk behaviors and early violence, adequately to complexity of these phenomena.

\section{Acknowledgements}

A lot of persons have a part in this work. First of all they are individuals, that were ready to fill enough extent battery of methods. We especially thanks to them. We thanks to persons, that agreed to perform studies in the following centers: The Center of Treatment of Adolescents with Drug DependenceMONAR in Gdansk, The Center of Treatment of Adolescents with Drug Dependence in Białystok, The Center of Treatment of Adolescents with Drug Dependence in Garwolin, the Adolescents Department of Clinic of Psychiatry in Lublin, the Department of Treatment of Dependency for Youth to 19 years old in the Hospital for Mental and Psychically Ill in Gniezno, the Adolescents Department of Psychiatry Clinic in Gdansk, Center of Dependent Persons Treatment in Torun, the Center of Treatment of Adolescents with Drug Dependence-MONAR in Łódź and MONAR in Poznań, the Rehabilitation-Educational Center for Dependent Youth in Częstochowa, the Psychiatric Department of Developmental Psychiatry in the Pediatric Center in Sosnowiec, Clinic for Treatment of Dependency in Olsztyn, Department of Eating Disorder in Psychiatry Clinic in Łódź, the Clinic of Children and Adolescents in Poznań, the Clinic of Developmental Age in Warsaw and Parents of studied persons. 


\section{REFERENCES}

Bruce, V., \& Young, A. (1998). In the eye of the beholder: The science of face perception. Oxford: Oxford University Press, 1998.

Behl, L. E., Conyngham, H. A., \& May. P. F. (2003). Trends in child maltreatment literature. Child Abuse \& Neglect, 27, 215-229. doi:10.1016/S0145-2134(02)00535-5

Benward, J., \& Densen-Gerber, J. (1975). Incest as a causative factor in anti-social behavior: An exploratory study. Contemporary Drug Problems, 4, 323-340.

Bifulco, A., Moran, P. M., Baines, R., Bunn, A., \& Stanford, K.(2002). Exploring psychological abuse in childhood: II. Association with other abuse and adult clinical depression. Bulletin of the Menninger Clinic, 66, 241-258. doi:10.1521/bumc.66.3.241.23366

Briere, J. N. (1992). Child abuse trauma: Theory and treatment of lasting effects. Newbury Park: Sage.

Bryer, J. B., Nelson, B. A., Miller, J. B., \& Kol, P. A. (1987). Childhood sexual and physical abuse as factors in adult psychiatric illness. American Journal of Psychiatry, 144, 1426-1430.

Brzozowska, A. (2004). Krzywdzenie dzieci jako czynnik ryzyka zachowań samobójczych-Przegląd literatury. Psychiatria Polska, 25, 29-36.

Cekiera, Cz. (1985). Patologia rodziny w środowisku narkomanów, alkoholików i samobójców. Zdrowie Psychiczne, 2.

Cicchetti, D. (1990) The organisation and coherence of socioemotional, cognitive, and representational development. In R. Thompson (Ed.), Nebraska Symposium on Motivation (pp. 259-366). Lincoln: University of Nebraska Press.

Claussen, A. I. E., \& Crittenden, P. M. (1991). Physical and psychological maltreatment: relations among types of maltreatment. Child Abuse \& Neglect, 15, 5-18. doi:10.1016/0145-2134(91)90085-R

Crittenden, P. (1988). Family and dyadic patterns of functioning in maltreating families. In K. Brown, C. Davies, \& P. Stratton (Eds.), Early prediction and prevention of child abuse. Chichester: Wiley.

De Young, M. (1982). The sexual victimization of children. McFarland: Jefferson.

Dube, S. R., Anda, R. F., Felitti, V. J., Chapman, D., Williamson, D. F., \& Giles, W. H. (2001). Childhood abuse, household dysfunction and the risk of attempted suicide throughout life span: Findings from the Adverse Childhood Experiences Study. Journal of American Medical Association, 286, 3089-3096. doi:10.1001/jama.286.24.3089

Edwards, V. J., Holden, G. W., Felitti, V. J., \& Anda, R. F. (2003). Relationship between multiple forms of childhood maltreatment and adult mental health in community respondents: Results from the Adverse Childhood Experiences Study. American Journal of Psychiatry, 160, 1453-1460. doi:10.1176/appi.ajp.160.8.1453

Evans, E., Hawton, K., \& Rodham, K. (2005). Suicidal phenomena and abuse in adolescents: A review of epidemiological studies. Child Abuse \& Neglect, 29, 45-58. doi:10.1016/j.chiabu.2004.06.014

Farmer, E., \& Owen, M. (1995). Child protection practice: Private risk and public remedies-Decision making, intervention and outcomes. London: Protection Work HMSO.

Fergusson, D. M., \& Mullen, P. E. (1999). Childhood Sexual Abuse: An evidence based perspective. Thousand Oaks: Sage.

Herman, J. L. (1981). Father-daughter incest. Cambridge: Harvard University Press.

Hund, A. R., \& Espelage, D. L. (2006). Childhood emotional abuse and disordered eating among undergraduate females: Mediating influence of alexithymia and distress, Child Abuse \& Neglect, 30, 393-407. doi:10.1016/j.chiabu.2005.11.003

Garbarino, J., Eckenrode, J., \& Bolger, K. (1997). The elusive crime of psychological maltreatment. In J. Garbarino, \& J. Eckenrode (Eds.), Understanding abusive families: An ecological approach to theory and practice (pp. 101-113). San Francisco: Jossey-Bass.

Hart, S. N., Brassard, M. R., \& Karlson, H. C. (1996). Psychological maltreatment. In J. Brier, L. Berliner, J. A. Bulkley, C. Jenny, \& T. Reid (Eds.), The APSAC handbook on child maltreatment (pp. 72-89). Thousand Oaks: Sage Publications Inc.

Higgins, D. J., \& McCabe, M. P. (2000). Multi-type maltreatment and the long-term adjustment of adults. Child Abuse Review, 9, 6-18. doi:10.1002/(SICI)1099-0852(200001/02)9:1<6::AID-CAR579>3.0. CO;2-W
Kent, A., \& Waller ,G. (2000). Childhood emotional abuse and eating psychopathology. Clinical Psychology Review, 20, 887-903. doi:10.1016/S0272-7358(99)00018-5

Kent, A., Waller, G., \& Dagnan, D. (1999). A greater role for emotional than physical or sexual abuse in predicting disordered eating attitudes: The role of mediating variables. International Journal of Eating Disorders, 25, 159-167. doi:10.1002/(SICI)1098-108X(199903)25:2<159::AID-EAT5>3.0.C $\underline{\mathrm{O} ; 2-\mathrm{F}}$

Luster, T., \& Small, S. A. (1997). Sexual maltreatment history and problems in adolescence: Exploring the effects of moderating variables. Journal of Marriage and the Family, 59, 131-142. doi: $10.2307 / 353667$

Moeller, T. P., Bachmann, G. A., \& Moeller ,J. R. (1993). The combined effects of physical, sexual and emotional abuse during childhood: Long-term health consequences for women. Child Abuse \& Neglect, 17, 623-640. doi:10.1016/0145-2134(93)90084-I

Moran, P. B., Vuchinich, S., \& Hall N. K. (2004). Associations between types of maltreatment and substance use during adolescence. Child Abuse \& Neglect, 28, 565-574. doi:10.1016/j.chiabu.2003.12.002

Ney, P. G., Fung, T., \& Wickett, A. R. (1993). Child neglect: The precursor to child abuse pre- and perinatal psychology. Pre-\& Perinatal Journal, 8, 95-112.

Kowalewicz, T., \& Malinowska, M. (1983). Charakterystyka warunków społeczno-psychologicznych i mechanizmów uzależnienia u młodzieży. Raport Etapowy. Warsaw: Instytut Psychoneurologiczny.

Malinosky-Rummell, R., \& Hansen, D. J. (1993). Long-term conesquences of childhood physical abuse. Psychological Bulletin, 114, 68-79. doi:10.1037/0033-2909.114.1.68

Miller, B. A., \& Downs, W. R. (1995). Violent victimization among women with alcohol problems. In M. Galanter (Ed.), Recent developments in alcoholism: Women and alcoholism (pp. 267-285). New York: Plenum.

Marek, T., \& Noworol, C. (1987). Zarys analizy skupień-Niehierarchiczne i hierarchiczne techniki skupiania. In J. Brzeziński (Ed.), Wielozmiennowe modele statystyczne $w$ badaniach psychologicznych. Warszawa-Poznań: PWN.

Marzec-Tarasińska, A. (1998). Sytuacja rodzinna młodzieży zażywającej środki odurzające. Stalowa Wola: Oficyna Wydawnicza Fundacji Uniwersyteckiej w Stalowej Woli.

Piotrowski, A. (1976). Niektóre psychospołeczne determinanty przyjmowania przez młodzież środków odurzających w latach 1969-1973. In M. Jarosz (Ed.), Wybrane zagadnienia patologii rodzinnej (pp. 150-151). Warsaw: GUS.

Pope, H. G., \& Hudson, J .I. (1992). Is childhood sexual abuse a risk factor for bulimia nervosa? American Journal of Psychiatry, 149, 455-463.

Root, M. P. (1989). Treatment failures: The role of sexual victimization in women's addictive behavior. American Journal of Orthopsychiatry, 59, 542-549. doi:10.1111/j.1939-0025.1989.tb02744.x

Salter, A. C. (2003). Pokonywanie traumy. Jak zrozumieć i leczyć doroste ofiary wykorzystywania seksualnego $w$ dzieciństwie. Poznań: Media Rodzina.

Simpson, T. L., \& Miller, R. W. (2002). Concomitance between childhood sexual and physical abuse and subsance use problems. A review. Clinical Psychology Review, 22, 27-77. doi:10.1016/S0272-7358(00)00088-X

Smolak, L., \& Murnen, S.K. (2002). A meta-analitic examination of the relationship between child sexual abuse and eating disorders. International Journal of Eating Disorders, 31, 136-150.

Stankowski, A. (1988). Narkomania-narkotyki-narkomani. Katowice: Uniwersytet Śląski.

Teicher, M. H., Samson, J. A., Polcari, A., \& McGreenery, C. E. (2006). Sticks, stones, and hurtful words: Relative effects of various forms of childhood maltreatment. The American Journal of Psychiatry, 163, 993-1000. doi:10.1176/appi.ajp.163.6.993

Thompson, A. E., \& Kaplan, C. A. (1996). Childhood emotional abuse. British Journal of Psychiatry, 168, 143-148. doi:10.1192/bjp.168.2.143

Wilsnack, S. C. (1984). Drinking, sexuality, and sexual dysfunction in 


\section{MAKARA-STUDZINSKA ET AL.}

women. In S. C. Wilsnack, \& L. J. Beckman (Eds.), Alcohol problems in women (pp. 189-227). New York: Guilford Press.

Wonderlich, S. A., Brewerton, T. D., Jocic, J., Dansky, B. S., \& Abbott,

D. W. (1997). Relationship of childhood sexual abuse and eating disorders. Journal of the American Academy of Child and Adolescent Psychiatry, 36, 1107-1115.

doi:10.1097/00004583-199708000-00018 